\title{
ARE RHEUMATIC FEVER AND RHEUMATOID ARTHRITIS ACCOMPANIED BY HAEMOLYTIC STREPTOCOCCAL BACTERIAEMIA ? *
}

\author{
B $\quad$ BY \\ OLE SYLVEST \\ Copenhagen
}

The view has sometimes been held that two rheumatic diseases-acute rheumatic fever and rheumatoid arthritis-are due to haemolytic streptococcal bacteriaemia.

\section{Haemolytic Streptococci in Acute Rheumatic Fever}

It must, however, be emphasized that the bacteria which have most frequently been found in the blood of patients suffering from rheumatic fever are streptococci belonging to the non-haemolytic group, probably - as already mentioned by Horder (1908) and Major (1912)-owing to a clinical confusion with patients suffering from subacute bacterial endocarditis. Now, however-because among other reasons of the often positive antistreptolysin titre in rheumatic fever patients-we regard this disease as caused by haemolytic streptococci; and we are therefore justified in taking special note of the reports recording a growth of haemolytic streptococci from blood. Buday (1890) and Singer (1898) were the first to succeed in isolating haemolytic streptococci from the blood of rheumatic fever patients. Osler (1901) regarded rheumatic fever as a weakened, mild pyaemia, possibly caused by pyogenic streptococci, and von Lingelsheim (1928) had a similar idea when he considered rheumatic fever as a metastatic strepticaemia originating from the throat. From post-mortem venous blood of a patient who had died of rheumatic fever and chorea, Lewis and Longcope (1904) isolated a haemolyticstreptococcus-like bacterium which caused polyarticular arthritis when injected into rabbits. In cultures from the blood of sixty rheumatic fever patients Cecil and others in 1929 found growth in thirty-five cases; these strains were distributed thus: thirty-three were Streptococcus viridans, and of the

- From The Medical Department, Sundby Hospital, Copenhagen; Senior Physician, Prof. H. C. Gram. two remaining ones, one was an ahaemolytic and the other a haemolytic streptococcus. Coburn (1931), who reared successively 221 cultures from the blood of eighty-four rheumatic fever patients, found streptococci in eight cases, in two of which he found haemolytic streptococci. In 1939 Green as well as Collis succeeded in cultivating haemolytic streptococci from the heart valves of persons who had died of rheumatic fever. If these microbes were also present in vivo-and if they are not due to a post-mortem phenomenon-bacteria must under such circumstances be expected to appear periodically in the blood stream.

\section{Haemolytic Streptococci in Rheumatoid Arthritis}

If, next, we consider rheumatoid arthritis, it is a well-known fact that since the beginning of 1930 a positive serum agglutination in the presence of haemolytic streptococci (Group A, Lancefield) has often been found in this disease at a titre of $1: 160$ or above, if the affection has persisted for some time. Since agglutinins-according to Kalbak (1946)-are conditioned by the rather widespread presence in the organism of living and dead bacteria (unlike the toxins, which may very well be produced even when bacteria are found in a small localized focus), Kalbak supposes that the positive agglutination for haemolytic streptococci found in old cases of rheumatoid arthritis-a reaction which according to Kalbak is presumably specific-would imply that in this disease these microbes are distributed throughout the organism-possibly in the form of a chronic sepsis.

Since positive findings of haemolytic streptococci in blood cultures from the two above-mentioned rheumatic diseases are either rather scarce (rheumatic fever) or have not been found (rheumatoid arthritis), conversely it seems justifiable-in order to 
throw light on the problem of bacteriaemia from haemolytic streptococci in rheumatic fever and rheumatoid arthritis-to subject the symptom of haemolytic streptococcal bacteriaemia to further analysis.

\section{The Present Investigation}

I intend therefore to give an outline of this disease, based on seventy-three of my own cases in which haemolytic streptococci of Group A were cultivated from the blood. The patients were not taken from any special department; they came from the whole country and were found through the medium of the State Serum Institute in Copenhagen, which in certain respects acts as a central laboratory for all Denmark.

Classification of Cases.-Classifying these seventythree cases of intravital haemolytic streptococcal bacteriaemia according to the site of the primary lesion, we have:

\begin{tabular}{|c|c|c|c|c|c|c|}
\hline \multicolumn{5}{|c|}{ Sore throat (source of infection unknown) } & \multicolumn{2}{|c|}{17 case } \\
\hline Sore throat (milk & infec & & $\cdots$ & & & \\
\hline Scarlatinal sore th & & & & & & \\
\hline \multirow{2}{*}{\multicolumn{5}{|c|}{$\begin{array}{l}\text { Sore throat in infectious mononucleosis } \\
\text { Otitis media and lateral sinus thrombosis }\end{array}$}} & & \\
\hline & & & & & & \\
\hline Pneumonia .. & & .. & .. & & & \\
\hline Pue & & .. & & . & & \\
\hline & & .. & $\cdots$ & $\cdots$ & & \\
\hline & & & & & & \\
\hline \multicolumn{4}{|c|}{ Thrombophlebitis of umbilical vein } & & & \\
\hline Pylephlebitis & & $\ldots$ & .. & & 1 & \\
\hline Pri & & & & & & \\
\hline
\end{tabular}

Symptoms.-The temperature is as a rule high. In a third of the cases the temperature was very irregular, and in half the cases the fever was accompanied by chills.

In almost half the cases there was a transitory skin eruption which varied considerably in type. A good fourth of the cases had joint complaints, mostly polyarticular and involving especially the large joints. In half of these cases the joint complaints were of relatively short duration, characterized by pain and tenderness but without noticeable changes. In contrast-in the other half of these cases-the joint complaints were more protracted, being characterized also by noticeable changes such as redness, swelling, and reduction of mobility. Considering all the patients with joint complaints together, intra-articular pus-formation was observed in 17 per cent., and growth of haemolytic streptococci was obtained in cultures from the affected joints in some of these. The sensorium was often affected, and in ten cases there was also meningitis. Often there was verrucous or ulcerous endocarditis, sometimes myocarditis as well, and frequently pneumonia, septic infarcts, and pleurisy. In almost every case there was splenomegaly, and in one-fifth albuminuria, sometimes with renal lesions. Often there was vomiting and diarrhoea as well as muscular abscesses. Anaemia, massively increased sedimentation rate, and high antistreptolysin titre (up to 16,000 ) were also frequently observed.

Mortality.-The total mortality of the entire series was 60 per cent. The great majority of these patients died in the first week, and no less than 38 per cent. of the total number died within the first four days of illness. The interval between the recognition of bacteriaemia and the return of the temperature to normal was found to be subject to rather wide variation, although most of the patients had a normal temperature within the first week.

Metastasis.-As will be seen, the clinical observations in haemolytic streptococcal bacteriaemia may differ greatly. Moreover these observations may be dominated by a primary focus. At other times it will be the bacteriaemia and its sequelae which entirely dominate the condition. Some forms of metastasis that may be particularly significant will be mentioned here, since it must be kept in mind that some of the bacteriaemic symptoms in question may be of short duration or possibly less marked, Thus there may be a patient who has become febrile following sore throat and who a few days later complains of pain in one knee joint. After a while the same patient becomes emaciated, anaemic, possibly also icteric; there is a red-spotted skin eruption, and the knee joint, still painful, is red, swollen, and sore. Some days later the skin eruption disappears. Sometimes the patient is drowsy, at others vociferous and confused, at times shaken by prolonged chills, then febrile with a fast pulse and accelerated respiration. From the still painful knee jointoperated upon by now-a purulent secretion filters out into the bandage. Within a few days the condition deteriorates further, and the patient succumbs to metastatic pneumonia.

In this case the articular metastasis dominates the disease. But besides the articular form the following may also be seen: a meningeal type in which the patient during the entire course of the disease shows marked rigidity of the neck and back; a typhoid form dominated by vagueness or unconsciousness; and a type with large abscesses in the tissue. All these are metastases which, provided the patient survives, will delay recovery for several weeks even after surgical procedures.

Hence it will be our task to ascertain whether the material of "the articular form" includes cases which can be interpreted as rheumatoid arthritis or rheumatic fever.

It actually turns out that two patients have suffered from rheumatoid arthritis. 
Case 1.-Three or four days before admission a man aged 64 with rheumatoid arthritis developed an erysipelas-like affection of the left thumb. The day before admission the patient's temperature was very high. Upon admission necrosis of the digital pulp was found, and the tissue was phlegmonous. On the fourth day after admission (about the eighth day of illness) the distal half of the thumb was gangrenous. Cultures of the blood showed growth of haemolytic streptococci. The next day the thumb was amputated. Two days later a systolic murmur was heard above the praecordia. The electrocardiogram showed a bundle branch block of the right side. The patient, who was febrile all the time, gradually deteriorated and died on the eighth day after admission (about the twelfth day of illness). Section showed among other things purulent pericarditis (the pus contained numerous gram-positive cocci). The heart was not opened.

Case 2.-A woman aged 52, who had had rheumatic fever when she was 25 and since then had suffered periodically from rheumatism in various joints, though never very seriously, about six months before admission developed swelling of most of her joints. During the month before admission the patient was febrile with chills: the raised temperature persisted throughout the patient's stay. On admission almost all the joints were found to be affected, with capsular swelling and reduction of mobility. The disease was diagnosed as rheumatoid arthritis. After a few days' hospitalization a small-spotted skin eruption appeared all over the body. On the twenty-ninth day after admission the patient was febrile with increased pain in the left foot and knee-joints. Haemolytic streptococci were cultivated from the blood. On the thirty-third day symptoms of phlebitis of the lower extremities appeared. A small-spotted skin eruption now appeared also on the arms. On the following days the patient suffered further from chills, and on the forty-second day haemolytic streptococci were again cultivated from the blood. Nodules from which haemolytic streptococci could be cultivated appeared on the trunk and extremities, and there was temporary conjunctivitis. On the hundred and sixth day a red-spotted skin eruption with numerous small pustules appeared on the back of the patient. The next day a large abscess formed on the medial side of the left femur; this was punctured and incised on several occasions, for the last time on the hundred and thirtyeighth day. On the hundred and ninetieth day a peroneal paresis was recognized. The patient was out of bed, but about the two-hundred and fiftieth day constantly increasing joint pains set in, and then praecordial pain with chills. Symptoms of pericarditis appeared. On the two hundred and sixty-first day a large-spotted skin eruption appeared (after salazopyrin?). Increasing dyspnoea and cyanosis set in, and the patient died on the two hundred and seventy-third day after admission (about the three hundred and third day of illness).

Discussion.-In the first case the bacteriaemia was probably caused by the phlegmonous process of the finger, in the second case it is hard to say any- thing about the site of the primary focus; it can only be emphasized that the chills, the numerous skin manifestations, and the formation of a large abscess are by no means typical of rheumatoid arthritis. In both patients death followed bacteriaemia. The combination of rheumatoid arthritis and haemolytic streptococci can here no doubt be interpreted as a coincidence. At most the haemolytic streptococcal infection may have had fuller scope in patients previously enfeebled by chronic disease. Further, Case 2 is peculiar in that it was the one among the sevety-three cases in which the bacteriaemia had apparently lasted longest. The feature otherwise most characteristic of haemolytic streptoccal bacteriaemia is that it is acute, thus forming an absolute contrast to rheumatoid arthritis. Another fact showing that rheumatoid arthritis is not followed by haemolytic streptococcal bacteriaemia is that all the patients suffering from the latter disease will-when the affection has persisted sufficiently long - show a much increased antistreptolysin titre. But, as is well known, an increased antistreptolysin titre in a rheumatoid arthritis patient is rather the exception than the rule.

Cases with Symptoms in the Joints.-If the frequently positive agglutination-titre in rheumatoid arthritis should be the result of an aetiologic connexion between this disease and haemolytic streptococci, the rheumatoid arthritis can, for the above-mentioned reasons, scarcely be regarded as a chronic bacteriaemia with haemolytic streptococci: A connexion between haemolytic streptococci and rheumatoid arthritis-if such a connexion exists at all -must be of a different nature. Altogether joint symptoms were found in twenty-seven of the seventythree cases of haemolytic streptococcal bacteriaemia. If we deduct the two above-mentioned cases of rheumatoid arthritis in which symptoms in the joint had lasted for a long time before the patients had bacteriaemia, and two cases of disseminated erythematous lupus which are also found in the material, twenty-three cases remain. In three of these cases the symptoms in the joints had appeared at the beginning of the disease and were vague, inconclusive, and transitory. In the remaining twenty cases the joint manifestations were more characteristic, so we confine ourselves to a consideration of these.

Are we in all these cases concerned with rheumatic fever? If first we consider the death rate of these twenty cases, we find that it amounts to 50 per cent. This goes decidedly against the view that the disease is rheumatic fever, in which death comparatively rarely occurs in the acute phase.

Four of the patients showed intra-articular pus formation. In three of these cases growth of haemolytic streptococci was obtained from this pus. The 
formation of pyarthron is also a factor that tells against rheumatic fever.

Only in six of the twenty cases was there a previous or initial sore throat, so we shall confine ourselves to a consideration of these cases.

Case 3.-Nine days before admission a man aged 20 suddenly felt low and febrile; there was slight pain on swallowing, and three or four days later vesicles appeared on the hands and feet; when he was admitted he also had dysuria. Whitish coverings were observed on the palatal arches, swelling of the angular glands, stethoscopic symptoms of endocarditis, skin eruption, pustules, and nodules on hands and feet. There was tenderness in the epigastrium. On the third day after admission (the twelfth of illness) stethoscopy showed symptoms of exudative pericarditis. The following day haemolytic streptococci were cultivated from a skin pustule, and nine days later haemolytic streptococci were cultivated from the blood. There was pain and tenderness of the shoulder joints on the twelfth day after admission, and on the next day a partial iridocyclitis appeared. Towards the end there was diarrhoea and jaundice, consciousness became clouded, and the patient died on the twenty-fifth day after admission (the thirty-fourth day of illness). (The metastases of the skin were now healed, and the eye metastasis was ameliorated.) Necropsy showed verrucous endocarditis of the mitral valve and aorta, myocarditis, fibrinous pericarditis, and septicemic infarcts in the spleen and kidney.

Case 4.-Eight days before admission a man, aged 22, developed sore throat. Two days before admission sugar, albumin, erythrocytes, and leucocytes were found in the urine. On admission only albuminuria was found, as also erythrocytes, leucocytes, and cylindroids in the urine. The patient was febrile; there was only slight redness of the fauces and some tenderness under angulus mandibulae. On the fifth day after admission (the thirteenth day of illness) facial erysipelas was observed, which subsided in two days. Two days later swelling of both wrists and ankle joints was observed. The condition deteriorated, and on the fourteenth day after admission (the twenty-second day of illness) haemolytic streptococci were cultivated from the blood. The patient died next day.

Section showed, among other things, glomerulonephritis, septicemic infarcts, pneumonic changes in both lungs, and accumulations of pus in the right hip and left ankle joints and subcutaneously on the left forearm and hand.

Case 5.-A man, aged 34, was operated on for piles. Three days after the operation the patient became febrile, and four days later there was covering and redness of fauces. Next day the temperature returned to normal. Seven days later sore throat again set in, with fever and chills. Then the patient was febrile for thirty-three days. Thirty-nine days after the operation there was pain and swelling of the left ankle joint and tenderness of the elbows. This diminished within about two weeks. On the forty-second day after the operation haemolytic streptococci were found in the blood. The patient was discharged on the fifty-sixth day after the operation.

Case 6. - A man, aged 25-who ten days before admission had been Calmette-vaccinated and eight days before had been vaccinated against diphtheria (second)-developed sore throat two days before admission and felt ill. The day before admission the patient was febrile, and a skin eruption appeared on the trunk. On admission a typical scarlatinal skin eruption was observed; there was incipient strawberry tongue, with marked diffuse redness of the fauces and moderate swelling of the angular glands. On the fourth day there was pain in the wrists. On the sixth day the patient was afebrile, but on the fourteenth day the temperature rose again. On the nineteenth day a measles skin eruption, Koplik's spots, and conjunctivitis set in. On the twenty-fourth day the skin eruption was declining, and there was desquamation on the face. There was temporary enlargement of the glands under sterno-cleido, chills and cough (stethoscopy of the lungs showed Sibilant rhonchi); and on the thirty-sixth day haemolytic streptococci were cultured from the blood. On the thirty-eighth day there was pain in the right shoulder and later on reduced mobility and redness of the shoulder. On the fifty-fourth day the temperature was normal, but there was still limited mobility and pain in the shoulder. On the eighty-first day the patient was discharged for ambulant massage and motion therapy of the right shoulder.

Case 7.-A woman, aged 19, had eclamptic fits in association with parturition, but was discharged healthy after hospitalization for seventeen days. Shortly after discharge she developed fever, furuncle in the throat, and swollen glands on the neck. The abscess perforated after a few days. Thirty-nine days after the birth the patient became icteric and febrile, and had a slight pain in the epigastrium and a few attacks of vomiting. Fortyfive days after parturition there was swelling and pain of the left wrist. The jaundice diminished, and the patient was again admitted to the hospital forty-nine days after parturition. She was very anaemic and had abscesses on the left side of the neck (along the vascular sheath) and on the left wrist. The temperature rose irregularly. On the fifth day of hospitalization haemolytic streptococci were cultivated from the blood. On the same day the abscesses were incised. The pain and accumulation of pus in the left wrist continued for a long time. The patient was discharged on the thirty-eighth day after hospitalization.

Case 8.-A man, aged 38, drank milk infected with haemolytic streptococci, after which he became febrile and got pain in the large joints. There was also said to be temporary redness, warmth and swelling of the left wrist. He was admitted to hospital six days after the onset of illness, with marked redness in fauces and symptoms of pneumonia on the left side. There was tenderness and reduction of mobility in some of the large joints. Haemolytic streptococci were cultivated from the blood. During hospitalization the patient was troubled by pains in the left shoulder and by numerous chills. The temperature was very erratic. Consciousness later became clouded; the patient deteriorated and 
died on the thirty-seventh day after admission (the forty-third of his illness).

Discussion.-Four of these cases, in spite of the sore throat and the joint affections, are not at all like rheumatic fever. (Case 3: pustules, nodules, jaundice, infarcts in spleen and kidney; Case 4: erysipelas, glomerulonephritis, infarcts in lungs, and accumulation of pus in joints and subcutis; Case 6: started as typical scarlatina, erratic temperature, and chills; Case 7: jaundice and abscesses.)

On the other hand, it cannot be denied that two cases (Cases 5 and 8 ) bear a considerable resemblance to rheumatic fever-but both were followed by chills, a symptom not usually observed in classical rheumatic fever.

\section{Conclusion}

The conclusion of this clinical study must therefore be that normally neither rheumatoid arthritis nor rheumatic fever is accompanied by haemolytic streptococcal bacteriaemia. Such a bacteriaemia, on the other hand, is as a rule distinguishable either by the site of the primary focus or by bacteriaemic metastases associated with chills-symptoms which do not occur in the two rheumatic diseases mentioned above.

\section{REFERENCES}

Buday, K. (1890). Orvosi Hetil, 34, 465. (cit. Centralbl. Bakteriol. Parasitenk., 1891, 10, 286.)

Cecil, R. L., Nicholls, E. E., and Stainsby, W. J. (1929). J. exp. Med., 50, 617 .
Coburn, A. F. (1931). " The Factor of Infection in the Rheumatic State." London. P. 56.

Collis, W. R. F. (1939). Lancet, 2, 817.

Green, C. A. (1939). Annals of the Rheumatic Diseases, $1,89$.

Horder, T. J. (1908). Clin. J. 32, 287. (cit. Thomson and Thomson, 1923; Ann. Pickett-Thomson Research Lab., 4, 18.)

Kalbak, K. (1946). Nord. Med., 31, 1997.

Lewis, M. J., and Longcope, W. T. (1904). Amer. J. med. Sci., 128, 601.

von Lingelsheim, W. (1928). In Kølle, W., and Wassermann A. von L., " Handbuch der path. Mikroorganismen." Jena Ausg. 3, Bd. 4, p. 825.

Major, R. H. (1912). Bull. Johns Hopk. Hosp., 23, 326. Osler. (1901).

Singer, G. (1898). “ "Ätiologie und Klinik des akuten Gelenkrheumatismus." Vienna. Pp. 416-17.

\section{Le Rhumatisme Articulaire Aigue et la Rhumatisme Chronique Progressif, sont-ils Accompagnés d'une Bactériémie avec Streptocoque Hémolytiques?}

\section{RÉSUMÉ}

Le résultat de l'examination clinique est que normalement ni le rhumatisme articulaire chronique progressif ni le rhumatisme articulaire aigu est accompagné de une bactériémie avec streptocoques hémolytiques. Au contraire, une telle bactériemie est ordinairement charactérisée ou par le foyer primaire ou par une métastase bactériémique en connection avec des frissons-des symptômes qui ne sont pas trouvés en les deux maladies rhumatismales mentionnées ci-dessus. 